\title{
Necrotizing Soft Tissue Infections of the Male and Female Breast: A Literature Review
}

\author{
Areta Kowal-Vern ${ }^{1,2}$, Daniela Cocco ${ }^{3}$, Marc R. Matthews ${ }^{1,4^{*}}$ \\ ${ }^{1}$ The Arizona Burn Center, Phoenix, USA \\ ${ }^{2}$ Research Department, Valleywise Health Medical Center, Phoenix, USA \\ ${ }^{3}$ Breast Surgical Services, Department of Surgery, Valleywise Health Medical Center, Phoenix, USA \\ ${ }^{4}$ Department of Surgery, Valleywise Health Medical Center, Phoenix, USA \\ Email: Marc_Matthews@dmgaz.org
}

How to cite this paper: Kowal-Vern, A., Cocco, D. and Matthews, M.R. (2021) Necrotizing Soft Tissue Infections of the Male and Female Breast: A Literature Review. Surgical Science, 12, 236-260. https://doi.org/10.4236/ss.2021.127026

Received: June 27, 2021

Accepted: July 25, 2021

Published: July 28, 2021

Copyright (c) 2021 by author(s) and Scientific Research Publishing Inc. This work is licensed under the Creative Commons Attribution International License (CC BY 4.0).

http://creativecommons.org/licenses/by/4.0/ (cc) (i) Open Access

\begin{abstract}
Background: Within the spectrum of necrotizing soft tissue infections (NSTI), necrotizing fasciitis (NF) has been characterized by tissue and fascial necrosis with systemic toxicity. The objective was to determine and summarize the frequency and characteristics of breast NF and NSTI in the literature. Methods: Cases were obtained through PubMed, Google Scholar, Google, and from published article reference sections. One hundred twenty-three cases were gleaned from 96 articles that reported NF and NSTI of the breast (1924 through 2021). Results: NF was reported in 70 and NSTI in 53 cases (111 women and 12 men). Patients presented with swollen, painful breasts, erythema, bullae, crepitus, necrosis, gangrene, fever, tachycardia, and neutrophilia. Fifty-nine of 123 (48.4\%) patients were septic on admission. The most frequent microorganisms were $\beta$ hemolytic Group A Streptococcus, and Staphylococcus aureus. Treatment consisted of antibiotics, mastectomy and debridement with flaps, skin grafts or primary and secondary closure. Forty-four $(63.0 \%)$ of the NF cases had chest wall involvement; of these, 18 (14.6\%) involved the breast secondarily, $P<0.0001$. There were twelve mortalities (9.8\%): eleven (9.0\%) with NF and one (0.8\%) with NSTI, $P=0.007$. Conclusions: Men and women with breast NF and NSTI presented with similar signs and symptoms and required the same emergent treatment as provided for NF and NSTI of the more common sites. As a time-sensitive disease, patients treated within 12 hours of admission had a better survival. Patients with NF were more likely to have sepsis on admission, a higher mortality, and fascial chest wall/muscle involvement than patients with NSTI.
\end{abstract}

\section{Keywords}

Breast, Necrotizing Fasciitis, Necrotizing Soft Tissue Infections, Chest Wall, 


\section{Introduction}

Within the spectrum of necrotizing soft tissue infections (NSTI), necrotizing fasciitis (NF) is characterized by tissue and fascial necrosis with associated systemic toxicity. For the more commonly reported cases of NF, mortality remains high, estimated between 20\% and 30\% [1] [2]. Based on 2003-2013 National Center for Health Statistics, NF has an incidence of 4.8 deaths per 1,000,000 and affects males more frequently (extremities and torso) [3]. In a review of the literature, Peetermanns et al. reported on 222 NSTI cases that required ICU admission with the following results: an incidence of $4 / 100,000 /$ year; $25 \%$ to $50 \%$ developed septic shock or required mechanical ventilation; $33 \%$ had acute kidney injury; or ICU admission was required due to comorbidities or postoperative wound care [4]. Most of the available literature is focused on the common presentations of necrotizing fasciitis, generally in men (extremities, chest and abdominal walls, head and neck, and Fournier's gangrene of the perineum and genitalia). Seen mainly in the female population, necrotizing fasciitis of the breast is a rare clinical entity and has been misdiagnosed for other diseases presenting after trauma, infection, or surgical intervention.

Patients with breast NSTI have the same risk factors and comorbidities as patients with the classic NF and NSTI: diabetes, renal disease, alcoholism, obesity, advanced age, surgical interventions, drug abuse, and immunosuppression [1] [2] [3]. NF originates from the breast parenchyma (primary) or involves the breast as a direct extension from an adjacent area such as the upper extremities, axilla, chest wall or face/neck (secondary) [5] [6]. Primary breast NF is commonly misdiagnosed as an abscess, mastitis, cellulitis, or inflammatory breast cancer, trauma, and contusion, leading to treatment delays [5] [6]. However, lactational mastitis, breast abscesses, and breast cancer may evolve into NSTI or NF within thirty days of initial drainage or surgery. Since breast involvement and mortality are reported mainly in single case or small series, they are excluded in the general NF or NSTI reviews or meta-analyses of the more common NF sites such as extremities, trunk, head/neck or perineum. Women have been included in the general NF and NSTI reports if they have extremity, head and neck or trunk infections. As in the more common locations, rapid clinical identification of NF and NSTI, and emergent surgical debridement of necrotic tissue are critical; delays to surgical intervention result in increased mortality regardless of gender or infection site [7]. Since NF of the breast is so rare and different from the usual locations where this disease usually develops, the objective was to review the current literature to determine, compare, and summarize the frequency, patient demographic characteristics, and treatment of breast NF and other NSTI diagnoses. 


\subsection{History of NF and NSTI}

The $5^{\text {th }}$ century B.C. renowned physician, Hippocrates, vividly described necrotizing fasciitis as a complication of erysipelas [8]. Erysipelas has been defined as an infection of the upper dermis and superficial lymphatics as opposed to cellulitis, which is in the deeper dermis and subcutaneous fat; especially in Europe, these are synonymous terms [9]. Both cause rapidly spreading erythema, swelling, pain, and edema that may progress to vesicles, bullae and ecchymoses.

Loudon provided a detailed description of necrotizing fasciitis, the "once-seenever-forgotten-disease," as it traversed through Europe in the $18^{\text {th }}$ and $19^{\text {th }}$ century, especially during the wars, (Peninsular, Battle of Waterloo, Napoleonic, Crimean), and on transport ships, where it was known as phagedena/hospital gangrene [10]. Although seen mainly in the military, "phagedena" did occur in England and Wales and had a high mortality of 30,475 patients in 1863 during an epidemic of scarlet fever, and another smaller occurrence in 1893 (78 patients) when there was an increase of deaths due to erysipelas and puerperal fever (uterine postpartum infection) [10]. The first English description of NSTIs was by three British physicians: Leonard Gillespie, Gilbert Blaine and Thomas Trotter, who called these infections phagedaenic ulcer, phagedena gangrenous, hospital gangrene, etc. in the late $18^{\text {th }}$ century [11].

In 1871 during the American Civil War, an Army surgeon, James Jones produced a treatise on hospital gangrene, reporting on 2642 cases with a $46 \%$ mortality [12] [13]. In World War I, the Belgian physician, Antoine Depage and others debrided the necrotic tissue and delayed primary closure; this maneuver along with newly developed antimicrobial interventions increased survival [14]. Mortality rates from gangrene decreased from $28 \%$ in World War I to $15 \%$ in World War II (1939-1945) [13]. As a result of rapid evacuation from the battlefield and antibiotics, none of the American soldiers developed gangrene during the Vietnam War [14]. The Joint Theater Trauma Registry (TTTR) established as a central repository of clinical casualty injury data in Operation Iraqi and Enduring Freedom reported that of the 562 completed records (2003-2006), there was only one patient with an ICD-9 code for necrotizing fasciitis [15]. Manring et al. compiled an interesting review on the treatment of war wounds throughout the centuries [16]. Although frequently quoted whenever an article about NF or NSTI is published, few reports indicate the relevance of the Meleny and Wilson observations about this disease process.

\subsection{Meleny and Wilson}

Historically, Wilson and Meleny were the most instrumental in identifying and describing NF and NSTI as we know them today. In 1924, Meleny documented the connection between 19 cases of $\beta$ hemolytic Streptococcus (19 cases) and gangrene in the extremities and trunk [17]. Wilson defined the disease severity and characteristics that required an acute observation, and a rapid decision to provide surgical debridement, removal of necrotic subcutaneous tissue, and fas- 
cia of the afflicted body part [18]. Wilson compared his own patients to those seen by Meleny, and in 1952 published a description of the clinical presentation and treatment of necrotizing fasciitis, Table 1. Current patient diagnostic parameters and treatment have not changed significantly from those patients encountered by Wilson and Meleny, especially the necessity for rapid surgical intervention at the time of admission.

\subsection{NF and NSTI of the Breast}

Many of the breast NF and NSTI case reports in the literature credited Shah et al. (2001) with the first report of NF occurring in the adult female breast [19] There were, however, earlier reports in 1924 by Probstein of an NSTI reported as gangrene of the breast [20]. In their case report, Shah et al. did not describe fascial involvement of the pectoral muscle or chest wall (the pre-operative diagnosis was necrotizing fasciitis): “... On gross examination the breast showed two haemorrhagic areas, each up to $30 \mathrm{~mm}$ across. Microscopically there was extensive necrosis of the breast tissue, subcutaneous fat and skin. Around the margin of necrosis, a rim of acute inflammation was present with associated focal vasculitis. Throughout the necrotic tissue numerous bacteria were seen without attendant inflammation; these were positive on Gram staining (Figure 1). The appearances were typical of necrotising fasciitis." [19] In the discussion, NF was

Table 1. Demographic characteristics of F. Meleny (1924) and B. Wilson (1952) patients with NF parameters [17] [18].

\begin{tabular}{ccc}
\hline Variables & Necrotizing Fasciitis [18] & Streptococcal Gangrene [17] \\
\hline Number & 20 & 23 \\
Age (years) & $45(31,60)$ & $32(23,49)$ \\
Gender (Male/Female) & $16 / 7$ & $18 / 2$ \\
Length of Stay (days) & $27(15,57)$ & $52(37,62)$ \\
Critically Ill \# (\%) & $10(43.5)$ & $18(90)$ \\
Gangrene \# (\%) & $11(47.8)$ & $19(95)$ \\
Temperature ${ }^{\circ} \mathrm{C}$ & $102.5(101,104)$ & $38(37,38)$ \\
Diminished Sensation (prick) \# (\%) & $13(59.0)$ & 0 \\
Hemoglobin (gm/dl) & $10(9.5,10.5)$ & $17.3(7.5,9.5)$ \\
White Blood Count (×10 $\left.{ }^{3} \mu \mathrm{L}\right)$ & -- & $12(5.5,15)$ \\
Day of Disease on Admit & $7(4,14)$ & $10(7,15)$ \\
Day of Disease Operation & $7(4,14)$ & $4.4 \pm 1.7(5)$ \\
Gangrene & -- & $3(15.8)$ \\
Erysipelas \# (\%) & $10(43.5)$ & 4 of 20 \\
Mortality \# (\%) & 2 of 23(4.65)
\end{tabular}

Median $(\mathrm{IQRT})=($ lower $25 \%$ interquartile range, upper $75 \%$ interquartile range); Number (percent) $=$ \# (\%); Meleny: 19 of 23 patients had cultured Streptococcus, Wilson: 5 (26\%) had cultured Streptococcus, 8 (42\%) had Staphylococcus, and 6 (32\%) had both Streptococcus and Staphylococcus. Some patients in the literature also complain of numbness of the breast, as noted by the diminished sensation above. 
Across a Century of Publications

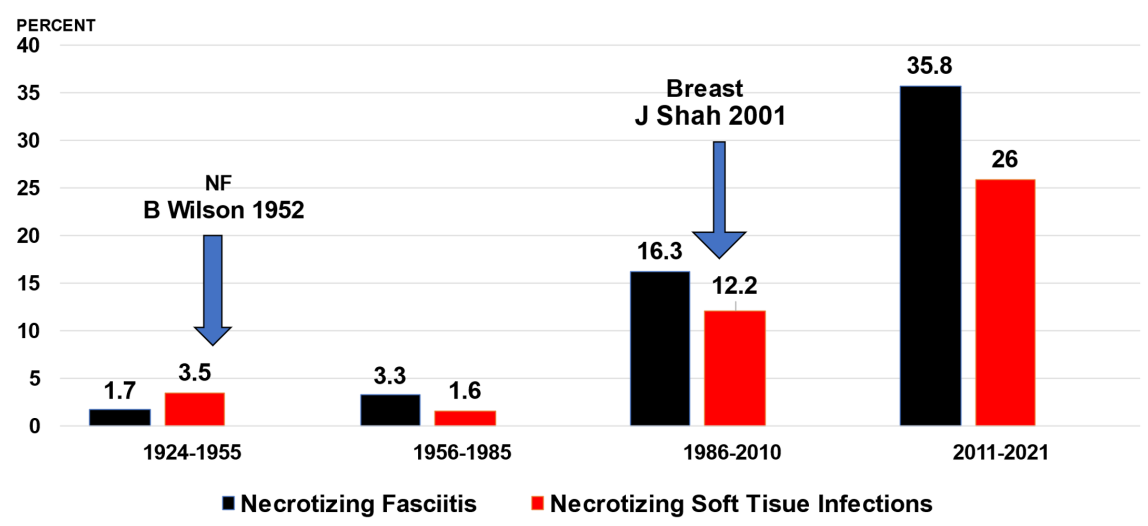

Figure 1. Both NF and NSTI of breast case reports and series have increased within the past ten years.

described as "a rare but serious progressive infection characterized by widespread necrosis of subcutaneous tissue and fascia with associated systemic toxicity." [19] This report, however, did note that: "Diagnostic incision of the affected site to inspect the underlying fascia should be performed at the earliest opportunity, with pus sent for urgent Gram stain and culture." [19] The keen observations of a case with NSTI defined the characteristics of necrotizing soft tissue infections to which NF belongs. It was emphasized in this case report that patients with breast NF and NSTI required the same rapid clinical observations and treatment as NF in other sites; otherwise, the rapid spread of an infection could evolve into an NF and increase mortality [19]. For the diagnosis of breast NF, it is important to document whether the breast and fascia of the underlying muscles and chest wall are affected by the infection or necrosis. If the fascia is not involved, then the diagnosis is a necrotic soft tissue infection (NSTI) of the breast. Since 1924, there have been abbreviated literature reviews with multiple case reports. The most recent NF and NSTI breast reviews have limited selected cases and time periods: Cai et al. with 40 cases between 1997-2018 and Konik et al. with 25 primary breast cases reported between 2001-2017 [21] [22]. Our literature review included all the cases reported in these two reviews; in addition, our review encompassed 1924 through 2021, and comprised patients with primary and secondary breast involvement: females, males, infants, in addition to women with lactational mastitis, abscesses, and surgical cases that progressed to NSTI and NF.

\section{Materials \& Methods}

\subsection{Case Report and Series Review}

There were 123 cases gleaned from 96 articles (1924 through 2020) that reported NF and NSTI of the breast. Literature searches were conducted through PubMed of the National Library of Medicine, Google Scholar, and from article reference sections [5] [6] [9] [10] [19] [20] [21]-[117]. All accessible English, Spanish, 
German, and French printed journal articles as case reports or series were identified if they pertained to breast gangrene, breast necrosis, necrotizing fasciitis of the breast, and necrotizing soft tissue infections. The specific terms searched for were: breast gangrene, necrosis, NF, NSTI, synergistic gangrene of the breast, and NF of the chest wall. Case reports which did not have "necrosis" or "gangrene" reporting abscesses, ulcerations, surgical soft tissue infections were not included in the title or case description. As noted in Figure 1, more than half of the case reports were published within the past decade. The landmark article recognized for NF was by Wilson in 1952, and for breast NF, Shah in 2001 [17] [19]. There may have been earlier publications than in 1924 about breast NF and NSTI, but they were not included in this literature review.

\subsection{Sources}

The major specialty journals were: 34 (35.4\%) Medicine (included Pharmaceuticals, Radiology, Tropical Medicine); 30 (31.3\%) Surgery (included Plastic Surgery and Trauma); 10 (10.4\%) in Breast; nine (9.4\%) in Case Reports; four (4.2\%) each in Pediatrics, Infectious Diseases, and Obstetrics/Gynecology; and one (1\%) in Pathology. Most of the articles originated from the United States 21 (22\%); the United Kingdom 16 (16.7\%); India 15 (15.6\%); four (4.2\%) each from Brazil, Korea, France; three (3.1\%) from Australia; two (2.1\%) each from Japan, Nigeria, Spain, Switzerland, Italy, Singapore, Saudi Arabia; and one (1.0\%) each from Germany, Belgium, Netherlands, Canada, Colombia, Argentina, China, Nepal, New Guinea, Morocco, Oman, Yemen, Kuwait, Egypt, and Israel.

\subsection{Inclusion Criteria}

The six study inclusion criteria for accepting a case as NF or NSTI have been the following variables: 1) patient age; 2) gender; 3) surgery or other; 4) tissue "necrosis or gangrene;" 5) presence or absence of fascial disease; and 6) mortality. For the diagnosis of necrotizing fasciitis, documentation of fascial involvement either through the surgical procedure, operative report, or histopathologic examination was required. Reports with incomplete or no reference to fascial involvement (that the fascia of muscles or chest wall were affected) were placed into the NSTI group. Figure 2 depicts the different articles titles in case reports that described either NF or NSTI of the breast and are part of this literature review. The article titles did not always reflect the appropriate disease state reported.

\subsection{Statistical Analysis}

Statistical analysis was performed with Statistica ${ }^{\circledR}$ (StatSoft, Tulsa, OK) descriptive statistics, one-way ANOVA, in post hoc comparisons, the Tukey test for unequal numbers was used. The nonparametric Mann Whitney U test was used for numeric results. Maximum Likelihood chi-squared was used for categorical variables. Patient demographics included: age, gender, primary or secondary involvement, NF, NSTI, location, presentation, admission sepsis, chest wall and 


\section{Percent of all breast NF and NSTI cases by article titles}

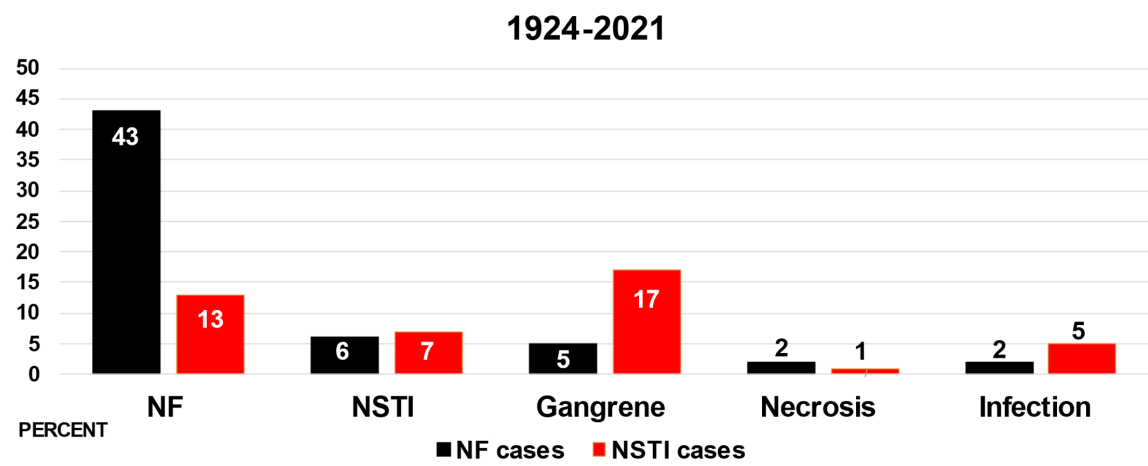

Figure 2. The abcissa identifies the article title and the ordinate reflects the percentage of cases that were actually reported as NF or NSTI. Most of the NF cases were titled as NF. NSTI cases were seen most frequently when the title contained "gangrene" or "infection."

muscle involvement, source and location of initial injury, laterality, surgery, mastectomy, debridement, initial white blood count, C-reactive protein, sodium chloride, creatinine, glucose, hemoglobin, platelets, microorganism (Type I polymicrobial and Type II monomicrobial), admission values for blood pressure, tachycardia, temperature, microorganisms, antibiotics, symptom duration prior to admission, length of stay (LOS), days in the intensive care unit (ICU), days ventilated, operations, reconstructive procedures, death, negative pressure wound therapy (NPWT), and hyperbaric oxygen therapy. Included were comorbidities such as diabetes, obesity, renal failure, hypertension and cardiovascular issues. Due to the small numbers, only the basic statistical analyses were performed. Primary breast NF was defined as the presenting disease process. Secondary breast NF was defined as breast tissue involvement, due to proximity of the spreading necrotic tissue, muscle, and fascia spread from an adjacent anatomical region. Comparisons were made between the NF and NSTI groups in terms of patient demographics, treatment, Type I and Type II infections, chest wall and muscle involvement, microorganisms and antibiotic use. The study was approved by the Institutional Review Board.

\section{Results}

There were 123 cases of which 70 (56.9\%) were classified as NF and 53 (43.1\%) as NSTI. Table 2 shows the demographic characteristics of 123 patients with NF and NSTI in the literature. Although NF and NSTI presentations for medical treatment were similar and required emergent diagnosis and treatment, patients with NF were more likely to have breast erythema, tissue crepitus, sepsis on admission, with more ICU days and operations. Of the twelve mortalities, 10 (8.2\%) patients who had sepsis on admission had a higher mortality than those without sepsis on admission 2 (1.6\%). For etiology, the distribution for NF and NSTI combined was: unknown 31 (25.2\%); lactation mastitis 27 (22.0\%); surgery/biopsy 26 (21.1\%); abscess 18 (14.6\%); ulcer 8 (6.5\%); other 13 (10.6\%). The 
Table 2. Demographic characteristics of patients with breast NF and NSTI.

\begin{tabular}{|c|c|c|c|c|c|}
\hline Parameters & $\begin{array}{c}\text { \# of entries } \\
\text { NF/NSTI }\end{array}$ & $\begin{array}{c}\text { NF + NSTI } \\
\text { Total }\end{array}$ & NF & NSTI & $P$ value \\
\hline Total number & -- & 123 & 70 & 53 & -- \\
\hline Age (years) & $70 / 53$ & $43(27,55)$ & $443(27,54)$ & $43(28,55)$ & 0.81 \\
\hline Gender (male/female) & $70 / 53$ & $12 / 111$ & $11 / 59$ & $1 / 52$ & 0.005 \\
\hline Length of stay (days) & $50 / 31$ & $21(12,42)$ & $21(10,42)$ & $21(14,42)$ & 0.92 \\
\hline Intensive care unit (days) & $25 / 5$ & $13(4,38)$ & $17(6,38)$ & $4(2,7)$ & 0.03 \\
\hline \# Operations & $68 / 47$ & $2(1,3)$ & $2(1,3)$ & $1(1,2)$ & 0.001 \\
\hline \multicolumn{6}{|l|}{ Vital Signs Median (IQRT) } \\
\hline Systolic pressure $(\mathrm{mmHg})$ & $31 / 13$ & $91(81-103)$ & $91(80.5,101.5)$ & $95(88,120)$ & 0.39 \\
\hline Diastolic pressure (mmHg) & $29 / 11$ & $60(50,64)$ & $58(50,60)$ & $62.5(46,72.5)$ & 0.30 \\
\hline Tachycardia (bpm) & $39 / 19$ & $116(111)$ & $114(102,133)$ & $110(100,130)$ & 0.59 \\
\hline Temperature ${ }^{\circ} \mathrm{C}$ & $35 / 19$ & $39(37.5,39)$ & $38.5(38,40)$ & $39(38.5,39)$ & 0.42 \\
\hline Symptoms (days) & $51 / 50$ & $4(2,7)$ & $4(2,7)$ & $5(2,7)$ & 0.34 \\
\hline Neutrophilia \# (\%) & $50 / 23$ & $56 / 23$ & $36(66.0)$ & $20(27.4)$ & 0.14 \\
\hline Body Mass Index $\left(\mathrm{m}^{2} / \mathrm{kg}\right)$ & $21 / 2$ & $23(36.2)$ & $33.3(27,36)$ & $29.0(27,30)$ & 0.45 \\
\hline \multicolumn{6}{|l|}{ Signs \& Symptoms \# (\%) } \\
\hline Pain & $68 / 53$ & $117(96.7)$ & $67(55.4)$ & $50(41.3)$ & 0.20 \\
\hline Erythema & $69 / 51$ & $102(85.0)$ & $65(54.2)$ & $37(30.8)$ & 0.001 \\
\hline Bullae/blisters & $66 / 49$ & $26(22.6)$ & $15(13.0)$ & $11(9.6))$ & 0.97 \\
\hline Peau d'Orange & $66 / 49$ & $5(4.4)$ & $1(0.9)$ & $4(3.5)$ & 0.08 \\
\hline Crepitus or tissue gas & $66 / 49$ & $32(27.8)$ & $28(24.4)$ & $4(3.5)$ & 0.0001 \\
\hline Gangrene & $70 / 53$ & $50(40.7)$ & $22(17.9)$ & $28(22.8)$ & 0.02 \\
\hline Admit sepsis \# (\%) & $69 / 53$ & $59(48.4)$ & $44(36.1)$ & $15(12.3)$ & 0.0001 \\
\hline *Type 1 & $63 / 42$ & $46(43.8)$ & $27(25.7)$ & $20(19.1)$ & -- \\
\hline${ }^{\dagger}$ Type II & $63 / 42$ & $57(54.3)$ & $35(33.3)$ & $22(21.0)$ & -- \\
\hline NWPT (days) & $9 / 7$ & $16(11-24)$ & $22(17,24)$ & $11(6,15)$ & 0.06 \\
\hline Lactational mastitis & $70 / 53$ & $26(21.1)$ & $7(5.7)$ & $19(15.4)$ & 0.001 \\
\hline \multicolumn{6}{|l|}{ Comorbidities \# (\%) } \\
\hline Diabetes & 22 & $22(18.0)$ & $13(10.6)$ & $9(7.3)$ & 0.82 \\
\hline Hypertension & 21 & $21(17.1)$ & $16(13.0))$ & $5(4.1)$ & 0.04 \\
\hline Obesity & 19 & $19(15.5)$ & $14(11.4)$ & $5(4.1)$ & 0.10 \\
\hline${ }^{\ddagger}$ Renal & 13 & $13(10.6)$ & $13(100.0)$ & 0 & 0.001 \\
\hline Breast cancer & 10 & $10(8.2)$ & $7(5.7)$ & $3(2.5)$ & 0.39 \\
\hline Cardiac & 9 & $9(7.3)$ & $6(4.9)$ & $3(2.4)$ & 0.53 \\
\hline Mortality \# (\%) & $70 / 53$ & $12(9.76)$ & $11(8.9)$ & $1(0.8)$ & 0.005 \\
\hline
\end{tabular}

Median $(\mathrm{IQRT})=($ lower $25 \%$ interquartile range, upper $75 \%$ interquartile range); \# $(\%)=$ number (percent); \# of entries NF/NSTI = cases reporting the data in each group; NF = necrotizing fasciitis; NSTI = necrotizing soft tissue infections; tachycardia (range beats/min 60 - 90); Systolic blood pressure (range 120 $90 \mathrm{mmHg}$ ); Diastolic blood pressure (range 60 - $80 \mathrm{mmHg}$ ); bpm = beats/minutes; temperature ${ }^{\circ}$ Centigrade (range 36.1 - 37.2); OR= operation; LOS = Length of stay; ICU= Intensive care unit; NPWT= negative pressure wound therapy; HTN= hypertension; ${ }^{\star}$ Type I infection(polymicrobial with aerobic and anaerobic organisms); ${ }^{\dagger}$ Type II infection (monomicrobial, Streptococcus Group A is most common; Staphylococcus aureus also; Type III (marine infection); ${ }^{\star}$ Renal issues developed during hospitalization. By Bonferroni correction, significance between the two groups had to be a $P$ value $\leq 0.0017$. NF patients had significantly more operations, erythema, crepitus or tissue gas, sepsis on admission and renal involvement than patients with NSTI. The NSTI group had significantly more patients with lactational mastitis than the NF group. 
"other" cohort consisted of trauma, boils, insect bites, injections, ulcers, intravenous drug abuse (IVDA), and contusions. The surgeries and biopsies consisted of the following: core biopsies, mammoplasty, breast implant and fat augmentation, arteriovenous fistula, lacerations, and cyst aspiration). Figure 3 illustrates the NF and NSTI cases in each group.

Within the age subsets, most of the patients were in the 15 - 55 age subset, Figure 4. The pediatric patients were mainly neonates with either omphalitis, necrotizing enterocolitis, urachal anomalies or chest wall involvement [33]. Table 3 shows the reported descriptions of the breast NF and NSTI. There were more bilateral mastectomies in patients with NF and no secondary involvement of the breast in the NSTI group. There were significantly more primary than secondary breast etiologies in both the NF and NSTI groups. Of interest, patients with NF were more likely to have chest wall involvement than patients with NSTI. Of the 45 cases with chest wall affected, 28 (26.7\%) were in the 105 (85.4\%)

\section{Breast NF and NSTI by etiology}

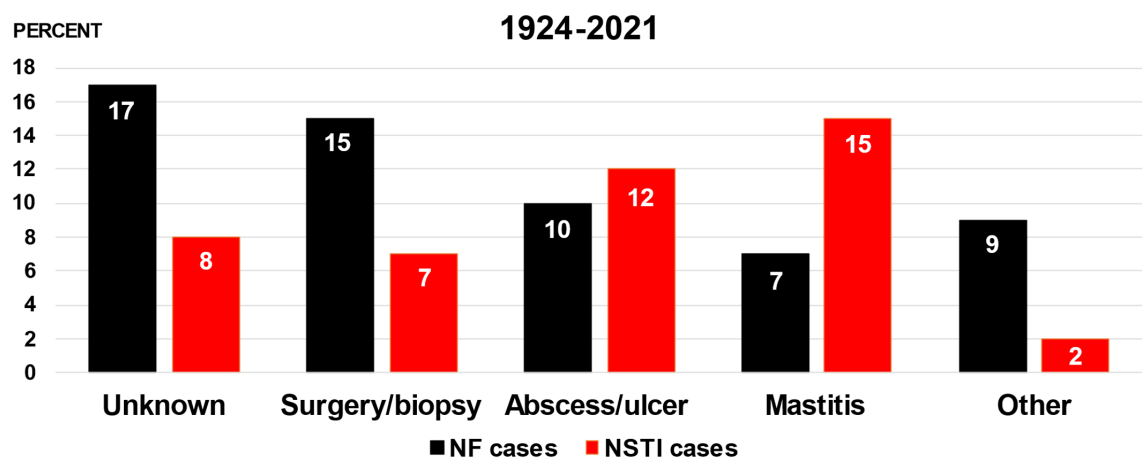

Figure 3. Thirty-two percent of NF breast cases occurred either within thirty days after a biopsy or surgical procedure or the etiology was unknown. Most of the lactational mastitis cases were NSTI.

Age subsets: 1924-2021

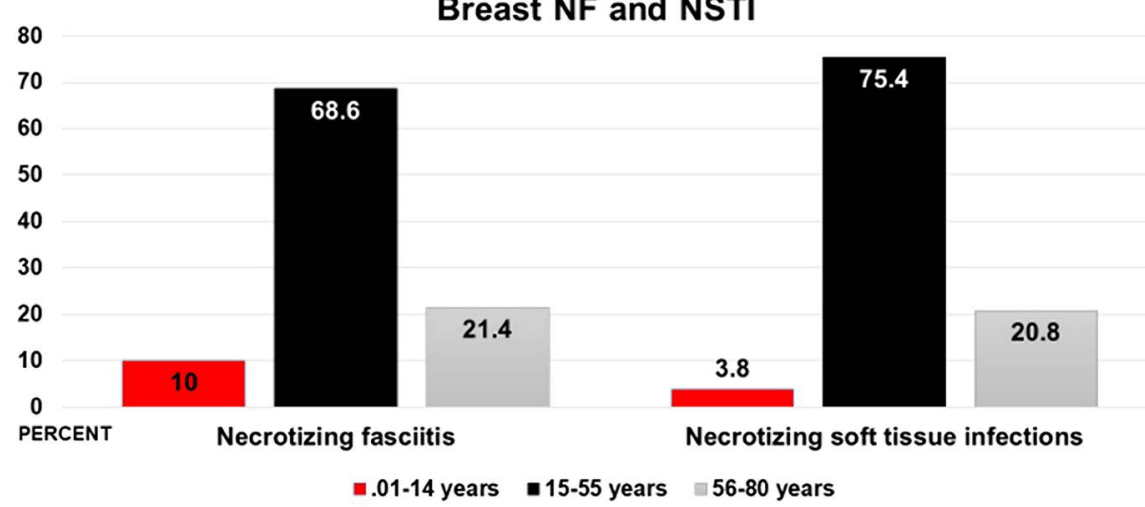

Figure 4. Most of the NF and NSTI cases described adult patients. NF and NSTI breast cases were described mainly in neonates. 
Table 3. Characteristics and treatment of breast NF and NSTI.

\begin{tabular}{|c|c|c|c|c|c|}
\hline Group & $\begin{array}{c}\text { \# of entries } \\
\text { NF/NSTI }\end{array}$ & $\begin{array}{c}\text { NF + NSTI } \\
\text { Total }\end{array}$ & NF & NSTI & $P$ value \\
\hline Number & & 123 & 70 & 53 & --- \\
\hline Breast laterality \# (\%) & & & & & 0.01 \\
\hline Left & $69 / 53$ & $48(38.3)$ & $31(25.4)$ & $17(13.9)$ & \\
\hline Right & $69 / 53$ & $56(45.9)$ & $24(19.7)$ & $32(26.2)$ & \\
\hline Bilateral & $69 / 53$ & $18(14.8)$ & $14(77.8)$ & $5(22.2)$ & \\
\hline Treatment \# (\%) & & & & & 0.0001 \\
\hline Unilateral mastectomy & $69 / 53$ & $45(37.0)$ & $34(28.0)$ & $11(9.0)$ & \\
\hline Bilateral mastectomy & $69 / 53$ & $11(9.0)$ & $10(8.2)$ & $1(0.82)$ & \\
\hline Partial mastectomy & $69 / 53$ & $17(13.9)$ & $11(9.0)$ & $6(4.9)$ & \\
\hline Debridement & $69 / 73$ & $49(40.2)$ & $14(11.5)$ & $35(28.7)$ & \\
\hline Location \# (\%) & & & & & 0.0001 \\
\hline Primary breast & $70 / 53$ & $105(85.4)$ & $52(42.3)$ & $53(43.1)$ & \\
\hline Secondary breast & $70 / 53$ & $18(14.6)$ & $18(14.6)$ & 0 & \\
\hline Chest wall & $70 / 53$ & $45(36.6)$ & $44(35.8)$ & $1(0.8)$ & \\
\hline Pectoral muscle & $70 / 53$ & $37(30.1)$ & $34(27.6)$ & $3(2.4)$ & \\
\hline${ }^{*}$ Upper extremity & $70 / 50$ & $15(12.5)$ & $12(10.0)$ & $3(2.5)$ & 0.06 \\
\hline *Axilla & $70 / 53$ & $15(12.2)$ & $12(9.8)$ & $3(2.4)$ & 0.045 \\
\hline Admission to surgery hrs \# (\%) & & & & & 0.0002 \\
\hline$<12$ & $70 / 53$ & $19(15.5)$ & $18(14.6)$ & $1(0.8)$ & \\
\hline$<24$ & $70 / 53$ & $41(33.3)$ & $27(22.0)$ & $14(11.4)$ & \\
\hline$<48$ & $70 / 53$ & $9(7.3)$ & $5(4.1)$ & $4(3.3)$ & \\
\hline$>48$ & $70 / 53$ & $10(8.1)$ & $5(4.1)$ & $5(4.1)$ & \\
\hline Unknown & $70 / 53$ & $44(35.8)$ & $15(12.2)$ & $29(23.6)$ & \\
\hline Reconstruction \# (\%) & $57 / 32$ & $17(19.1)$ & $12(13.5)$ & $5(5.6)$ & 0.53 \\
\hline STSG \# (\%) & $66 / 48$ & $47(41.0)$ & $25(22)$ & $22(19)$ & 0.39 \\
\hline LRINEC score median (IQRT) & $11 / 5$ & $7.5(5,8)$ & $5(4,8)$ & $8(8,9)$ & 0.06 \\
\hline
\end{tabular}

$\mathrm{NF}=$ necrotizing fasciitis; NSTI = necrotizing soft tissue infections; LRINEC score = Laboratory risk indicator for necrotizing fasciitis; \# of entries NF/NSTI = cases reporting the data in each group; Median $($ IQRT $)=($ lower 25\% interquartile range, upper 75\% interquartile range $)$; hrs $=$ hours; Number $($ Percent $)=$ \# (\%); * additional locations that required debridement of necrotic tissue. Primary $=$ NF and NSTI originate in the breast itself. Secondary $=$ NF extends to the breast from the surrounding tissues. By Bonferroni correction, significance between the two groups had to be a value $\leq 0.004$. NF patients had significantly more mastectomies, secondary breast NF, and muscle and chest wall involvement than patients with NSTI.

primary breast infections, and $17(94.4 \%)$ in the 18 (14.6\%) secondary breast cases, $P<0.0001$. Most of the patients with lactation mastitis had NSTI. As can be seen in the literature, a significant number of both NF and NSTI breast cases were operated on within the first 24 hours of admission. There were also several cases where the following modalities were used for debridement: two patients 
with hot boric acid packs; two with Eusol (a basic hypochlorous acid solution used to heal wounds by secondary intention) and hydrogen peroxide; one each with Dakin's solution and flaxseed poultices.

\subsection{Gender Differences}

Although there were more female patients, both sexes presented with similar sign and symptoms. In the NF group, male patients had longer LOS (median 44 versus 20 days, $P=0.002$ ); ICU (median 45 versus 8 days, $P<0.0002$ ); higher number of operations (3.5 versus 2.0, $P=0.005$ ); and lower BMI indices (median 27 versus 35, $P=0.03$ ) than the female patients. In contrast, 9 of 12 men (75\%) were more likely to have secondary breast involvement than the women ( 9 of $111,8 \%)$. There was no significant difference in mortality, which was lower than that reported in other locations of NF and NSTI in the literature.

\subsection{Microorganisms and Antibiotics}

The microorganisms of breast NF and NSTI were the same as seen in other locations. Table 4 lists the most frequent microorganisms: $\beta$ hemolytic Group A Streptococcus (GAS), Staphylococcus aureus and Pseudomonas aeruginosa. Type I infections were polymicrobial and had the full gamut of aerobic and anaerobic species seen (Streptococcus, Staphylococcus, Proteus, Candida, et cetera). Type II infections were usually $\beta$ hemolytic Group A Streptococcus, Staphylococcus aureus, and methicillin resistant Staphylococcus aureus (MRSA). Unusual microorganisms were frequently listed in the article titles. A virulent deadly strain of Klebsiella species with a $40 \%$ mortality was seen in Asia and other areas; it was not reported in patients with breast NF or NSTI, but rather in other body locations [116] [117]. The preoperative antibiotics for breast cases were documented in 50 (56.2\%) NF and 39 (43.8\%) NSTI; postoperative antibiotics were recorded in 59 (60.2\%) NF and 39 (39.8\%) NSTI cases, Table 5. There

Table 4. Microorganisms cultured in NF and NSTI breast cases.

\begin{tabular}{cccc}
\hline 115 cases \# (\%) & NF + NSTI & NF & NSTI \\
\hline GAS & $31(27.4)$ & $23(20.4)$ & $8(7.1)$ \\
Staphylococcus aureus & $22(19.5)$ & $11(9.7)$ & $11(9.7)$ \\
Staphylococcus species & $23(20.2)$ & $16(14.0)$ & $7(6.1)$ \\
Pseudomonas aeruginosa & $12(10.5)$ & $6(5.3)$ & $6(5.3)$ \\
Escherichia coli & $11(9.7)$ & $4(3.5)$ & $7(6.1)$ \\
Streptococcus species & $11(9.7)$ & $9(8.0)$ & $2(1.8)$ \\
Enterococcus faecalis & $10(8.8)$ & $3(2.6)$ & $7(6.1)$ \\
Bacteroides & $9(7.8)$ & $2(1.7)$ & $7(6.1)$ \\
Proteus vulgaris + mirabilis & $8(7.0)$ & $1(0.9)$ & $7(6.1)$ \\
Miscellaneous + fungi & $23(20.2)$ & $18(15.8)$ & $5(4.4)$
\end{tabular}

Number $($ percent $)=\#(\%) ;$ GAS $=\beta$ hemolytic Group A Streptococcus , NF = necrotizing fasciitis; NSTI = necrotizing soft tissue infection. 
Table 5. Pre- and postoperative antibiotics used in NF and NSTI breast cases.

\begin{tabular}{|c|c|c|c|}
\hline Antibiotics & $\mathrm{NF}+\mathrm{NSTI}$ & NF & NSTI \\
\hline Preoperative (89 cases) & $50 / 39$ & & \\
\hline Penicillin/amoxicillin-clavulanic acid & $34(38.2)$ & $17(19.1)$ & $17(19.1)$ \\
\hline Vancomycin & $24(27.0)$ & $15(17.0)$ & $9(10.1)$ \\
\hline Clindamycin & $19(21.4)$ & $12(13.5)$ & $7(8.0)$ \\
\hline Imipenem + other “-nems" & $14(16.0)$ & $5(5.7)$ & $9(10.2)$ \\
\hline Metronidazole & $13(14.6)$ & $8(9.0)$ & $5(5.6)$ \\
\hline Amikacin/gentamycin & $12(13.5)$ & $8(9.0)$ & $4(4.5)$ \\
\hline Piperacillin/tazobactam & $7(7.7)$ & $5(5.5)$ & $2(2.2)$ \\
\hline Zyvox/zosyn & $7(8.1)$ & $6(7.0)$ & $1(1.2)$ \\
\hline Postoperative (98 cases) & $59 / 39$ & & \\
\hline Penicillin/amoxicillin-clavulanic acid & $31(31.6)$ & $19(19.4)$ & $12(12.2)$ \\
\hline Vancomycin & $26(26.5)$ & $14(14.3)$ & $12(12.2)$ \\
\hline Clindamycin & $22(22.5)$ & $14(14.2)$ & $8(8.2)$ \\
\hline Metronidazole & $19(19.4)$ & $11(11.2)$ & $8(8.2)$ \\
\hline Amikacin/gentamycin & $19(19.4)$ & $13(13.3)$ & $6(6.1)$ \\
\hline Imipenem + other "-nems" & $16(16.5)$ & $8(8.3)$ & $8(8.3)$ \\
\hline Zyvox/zosyn & $16(16.5)$ & $8(8.3)$ & $8(8.3)$ \\
\hline Piperacillin/Tazobactam & $15(15.5)$ & $11(11.3)$ & $4(4.1)$ \\
\hline
\end{tabular}

Number $($ percent $)=\#(\%)$ GAS $=\beta$ hemolytic Group A Streptococcus , NF $=$ necrotizing fasciitis; NSTI = necrotizing soft tissue infection.

were multiple combinations of antibiotics used on admission: penicillin, piperacillin, vancomycin, clindamycin, amoxicillin-clavulanic acid, metronidazole, and gentamicin. The most frequent antibiotics administered after culture and sensitivities were: clindamycin, metronidazole and vancomycin. There was also a variety of other antibiotics and fungicides. Fungi were rare: there were only a few cases of Candida albicans and Fusarium species.

\subsection{Differential Diagnosis with Other NSTI}

During this review, there were several other disease processes that had necrosed breast tissue and gangrene: anticoagulant-induced gangrene of the breast, pyoderma gangrenosum, purpura fulminans, and Sweet syndrome. Flood et al. described a 40-year-old female who developed gangrene of the right breast several days after starting Dicumarol for thrombophlebitis of the right saphenous vein in her right leg [118]. The patient required debridement of the necrotic breast tissue; pathology revealed hemorrhage, thrombosed veins with many leukocytes and fibroblasts [118]. This case was considered thrombophlebitis migrans dissemina because of the involvement of the lung and extremity [118]. Although rare, a number of these cases with necrosis of the breast have been reported after 
treatment with warfarin (coumadin) [119].

Other conditions that presented as NSTI were pyoderma gangrenosum cases, a "rapid spreading ulceration and necrosis similar to synergistic gangrene." [120] A patient presented four days after a breast reduction with fever, painful, swollen breasts and erythema not affecting the suture lines; with no response to antibiotics, she responded quickly to immunosuppressive treatment with cyclosporin or tacrolimus [120]. Pyoderma gangrenosum, a neutrophilic dermatosis, is a hallmark of pathergy and can occur spontaneously or after slight injury; since it can present as ulceration after breast surgery, it must be distinguished from NF and NSTI; the treatment is steroids or immunosuppressive therapy rather than debridement or mastectomy [121] [122]. It usually occurs after bilateral mammoplasty or autologous reconstruction [121] [122].

Gesakis et al. reported a 45-year-old woman who presented with a septic picture and an enlarged left breast with erythema, blisters, necrosis and tissue air on ultrasound [123]. The LRINEC score was 8, and she underwent a mastectomy. Histopathologic examination of the tissue revealed primary spindle cell sarcoma of the breast [123]. Previous radiation treatment, especially for breast cancer and non-Hodgkin's lymphoma, is the main risk factor for developing breast sarcomas; this patient did not have radiation therapy previously [123].

Young et al. reported on Sweet syndrome, which was a case of breast hidradenitis with multiple breast abscesses and mislabeled as NF [124]. Necrotizing Sweet syndrome (a variant of neutrophilic dermatosis) was described as an NSTI in four patients; one case involved the pectoralis major muscle in a transsexual male and three others had their disease manifest in the lower extremity [125]. [126]. This condition manifested pathergy, mimicked NF and was successfully treated with corticosteroids and cyclosporin [125] [126].

\subsection{Laboratory Parameters of Breast NF and NSTI}

Table 6 indicates the laboratory values that were frequently reported. Most

Table 6. Laboratory characteristics of breast NF and NSTI in the literature.

\begin{tabular}{|c|c|c|c|c|}
\hline \multicolumn{2}{|c|}{ (Number tested for each value) } & \multirow{2}{*}{$\begin{array}{c}\text { Expected ranges } \\
--\end{array}$} & \multirow{2}{*}{$\begin{array}{c}\mathrm{NF} \\
66\end{array}$} & \multirow{2}{*}{$\begin{array}{c}\text { NSTI } \\
49\end{array}$} \\
\hline Number & (115) & & & \\
\hline White blood count & $(44 / 21)$ & $4.2-10.210^{3} / \mu \mathrm{L}$ & $14.5(8,23)$ & $18(14,23)$ \\
\hline Hemoglobin & $(22 / 11)$ & $11.6-14.8 \mathrm{~g} / \mathrm{dl}$ & $9(8,12)$ & $11(9,13)$ \\
\hline C-reactive protein & $(23 / 9)$ & $\leq 5.0 \mathrm{mg} / \mathrm{L}$ & $150(52,316)$ & $167(41,374)$ \\
\hline Sodium chloride & $(19 / 2)$ & $137-145 \mathrm{mmol} / \mathrm{L}$ & $133(128,139)$ & $134(131,137)$ \\
\hline Blood urea nitrogen & $(18 / 3)$ & $7-17 \mathrm{mg} / \mathrm{dL}$ & $28(20,42)$ & $74(35,116)$ \\
\hline Creatinine & $(27 / 6)$ & $0.52-1.04 \mathrm{mg} / \mathrm{dL}$ & $2(1,3)$ & $1.5(0.9,2)$ \\
\hline Glucose & $(22 / 5)$ & $74-106 \mathrm{mg} / \mathrm{dL}$ & $143(110,300)$ & $140(108,187)$ \\
\hline
\end{tabular}

Median $($ IQRT) $=($ lower 25\% interquartile range, upper $75 \%$ interquartile range); statistics were based on 20 or more cases reporting laboratory results. NF = necrotizing fasciitis; NSTI = necrotizing soft tissue infections. 
patients had a neutrophilia, C-reactive protein, BUN, and creatinine. Glucose levels were reported mainly for the patients with diabetes; of the five HgAlc levels reported (median 10.8\%), four were in the NF group. The literature laboratory results were few with mainly the WBC count reported, $38 \%$ of the time for NF and $18 \%$ for NSTI. With clinically painful, swollen, gangrenous, and discolored breasts (with and without sepsis), most cases reported rapid diagnosis, surgical intervention within 24 hours of presentation, and broad-spectrum antibiotics for adequate treatment and survival.

\section{Discussion}

This comprehensive literature review of NF and NSTI of the breast has documented and summarized literature case reports and series that have been published between 1924 and 2021. More commonly diagnosed in women, 10.4\% of cases occurred in men. Patients with breast NF and NSTI presented with the same signs and symptoms as patients with the more commonly seen extremity, trunk, and neck areas. Fifty-nine (48.4\%) patients presented with sepsis on admission. As noted by Wilson, deterioration and expansion of the necrosis or gangrene in the presence of antibiotics was a prompt for surgical debridement [17]. Streptococcus (GAS) and Staphylococcus species were the most common organisms, although most of the known aerobes, anaerobes, and fungi were cultured. There was an $8.9 \%$ mortality rate in patients who developed NF of the breast.

Both patient groups required debridement of necrotic tissue but patients with NF were more likely to have simple, radical, or partial mastectomies, while NSTI patients had debridement mainly. Twenty-four (22.4\%) of 107 reported patients benefited from negative pressure wound therapy (NPWT) during the healing process; hyperbaric oxygen therapy was rarely applied. Kostaras et al. also had success applying NPWT in the healing of breast wounds [127]. Since NF and NSTI are mainly clinical diseases that require emergent treatment, occasional pathology reports were histopathologic descriptions of either the mastectomy specimens, or biopsies composed of resected edematous, necrotic, or inflamed skin, fat, subcutaneous tissue, fascia and thrombosed blood vessels [128]. With the urgency of making the diagnosis, physicians in most cases reported results on tissue Gram stains from diseased tissue areas.

Cai et al. and Konik et al. presented cases, all of which have been included in the statistical analysis of this literature review [21] [22]. Abur et al. reported on the only large series of 39 women with breast NF, 28 (74.4\%) of whom were $<31$-years-old and presented with poorly treated lactation mastitis and breast abscesses [129]. The patients had serial wound debridement, skin grafts or wound cleansing; the mortality rate for the 39 women was $10.4 \%$, which was like that of the current study [129]. Marchesi et al. found 18 of 3782 papers related to $\mathrm{NF}$ after an aesthetic procedure and two cases of NF after augmentation mammoplasty [130]. One of these patients had debridement and delayed implant re- 
construction 12 weeks later [130]. The other patient (reported by Sharma) had NF of the abdominal wall after liposuction for augmentation mammoplasty but no breast complications [131]. In preparation for bilateral breast augmentation with fat injection, another patient developed NF of the bilateral thighs and waist where liposuction was performed [132]. These last two cases demonstrated that liposuction to obtain body fat for breast augmentation can be complicated by either NF or NSTI.

\section{LRINEC Score}

To distinguish NF from NSTI, the laboratory risk indicator for necrotizing fasciitis (LRINEC) score was introduced by Wong et al. in 2004 [133]. This scoring system consisted of numerical values assigned for the following laboratory tests: white blood count, hemoglobin, C-reactive protein, sodium chloride, BUN, serum creatinine at the time of initial patient assessment. Scores at $\geq 6$ were considered to be strongly suspicious for necrotizing fasciitis [133]. Several authors have analyzed these results with variable ranges of specificity and sensitivity [134] [135] [136] [137]. Abdullah classified NF case reports, expert articles, reviews and retrospective observational studies by levels of clinical evidence [137]. Sixteen (13\%) of 123 patients received LRINEC scores in the breast case reports or series. Final diagnosis was more frequently made on clinical presentation, ultrasound, chest X-ray, CT scan or MRI, or surgical consult. Due to the need for emergent surgical debridement, laboratory assessment to produce an LRINEC score was often inadequate. In all cases and reports, the clinical conclusions were that this was a time-sensitive condition that required a swift, accurate clinical assessment (radiologic diagnostic modalities if time allowed), definitive surgical interventions, and broad-spectrum antibiotics for patient survival in both the NF and NSTI cases.

\section{Limitations}

The major limitations of this review were related to the availability of data from the case reports analyzed. One difficulty in assessing the actual diagnoses was the incomplete surgical documentation of fascial involvement in some of the NF and NSTI cases reports and series.

Operative and histopathologic reports did not always determine whether the extension of the disease process involved necrosis or inflammation of the fascia of the pectoralis muscle or chest wall. Occasional single breast cases reported in NF or NSTI group publications did not have adequate details for inclusion in this review. The categorization into NF and NSTI groups was based on the data supplied in the case reports. If data was incomplete about the involvement of the fascia, the cases were assigned to the NSTI group.

\section{Conclusions}

This was a comprehensive review and categorization of the NF and NSTI of 
breast cases and series reported in the literature from 1924 through 2021. Patients with breast NF and NSTI presented with the same signs and symptoms and required the same treatment as provided in NF and NSTI cases of the more common sites. Although the disease was mainly reported in females, males were also at risk and had NF predominantly. Besides diabetes, hypertension, kidney failure, immunosuppression and obesity as comorbidity risk factors, women with lactational mastitis, abscesses and breast cancer were at risk, especially for NSTI. Patients with secondary breast involvement were more likely to have NF and local fascia, muscle and/or chest wall disease. The major organisms were GAS and Staphylococcal species like aureus, coagulase negative and MRSA; many other organisms were also reported.

The physician has no control as to when patients present for medical care. Although NF and NSTI are rare diseases, patients who present with very painful, swollen, discolored breasts with necrosis, gangrene, trauma, cellulitis, abscesses, surgical soft tissue infections (SSTI) or sepsis require immediate attention, and diagnoses to rule out these conditions. Once diagnosed, surgical intervention within 12 hours of presentation, and broad-spectrum antibiotics are paramount for adequate treatment and survival. A high index of suspicion, early diagnosis, aggressive surgical treatment and antibiotics continue to be the gold standard, with optimal timing of initial debridement for both NF and NSTI within the first 12 hours of admission [138] [139].

\section{Conflicts of Interest}

The authors declare no conflicts of interest regarding the publication of this paper.

\section{References}

[1] Stevens, D.L. and Bryant, E.A. (2017) Necrotizing Soft-Tissue Infections. New England Journal of Medicine, 377, 2253-2265. https://doi.org/10.1056/NEJMra1600673

[2] Bonne, S. and Kadri, S.S. (2017) Evaluation and Management of Necrotizing Soft Tissue Infections. Infectious Diseases Clinics of North America, 31, 497-511. https://doi.org/10.1016/j.idc.2017.05.011

[3] Arif, N., Yousfi, S. and Vinnard, C. (2016) Deaths from Necrotizing Fasciitis in the United States, 2003-2013. Epidemiology \& Infection, 144, 1338-1344. https://doi.org/10.1017/S0950268815002745

[4] Peetermanns, M., de Prost, N., Eckmann, C., Norrby-Teglund, A., Skrede, S. and De Walde, J.J. (2020) Necrotizing Skin and Soft-Tissue Infections in the Intensive Care Unit. Clinical Microbiology and Infection, 26, 8-17. https://doi.org/10.1016/j.cmi.2019.06.031

[5] Yaji, P., Bhat, B., Harish, E. (2014) Primary Necrotising Fasciitis of the Breast: Case Report and Brief Review of Literature. Journal of Clinical and Diagnostic Research, 8, ND01-ND02. https://doi.org/10.7860/JCDR/2014/9281.4558

[6] Konik, R.D., Cash, A.D. and Huang, G.S. (2017) Necrotizing Fasciitis of the Breast Managed by Partial Mastectomy and Local Tissue Rearrangement. Case Reports in Plastic Surgery \& Hand Surgery, 4, 77-80. 
https://doi.org/10.1080/23320885.2017.1364970

[7] Al Alayed, K., Tan, C. and Daneman, N. (2015) Red Flags for Necrotizing Fasciitis: A Case Control Study. International Journal of Infectious Disease, 36, 15-20. https://doi.org/10.1016/j.ijid.2015.04.021

[8] Descamps, V., Aitken, J. and Lee, M.G. (1957) Hippocrates. Epidemics. Heinemann, for Harvard University Press, London, 24-43.

[9] Stevens, D.L., Bisno, A.L., Chambers, H.F., Dellinger, E.P., Goldstein, E.J.C., Gorbach, S.L., Hirschmann, J.V., Kaplan, S.L., Montoya, J.G. and Wade, J.C. (2014) Practice Guidelines for the Diagnosis of Skin and Soft Tissue Infections: $2014 \mathrm{Up}$ date by the Infectious Diseases Society of America. CID, 59, e10-e52. https://doi.org/10.1093/cid/ciu296

[10] Loudon, I. (1994) Necrotising Fasciitis, Hospital Gangrene, and Phagedena. Lancet, 344, 1416-1419. https://doi.org/10.1016/S0140-6736(94)90574-6

[11] Hakkarainen, T.W., Kopari, N.M., Pham, T.N. and Evans, H.L. (2014) Necrotizing Soft Tissue Infections: Review and Current Concepts in Treatment, Systems of Care, and Outcomes. Current Problems in Surgery, 51, 344-362.

https://doi.org/10.1067/j.cpsurg.2014.06.001

[12] Jones, J. (1871) II. Investigations upon the Nature, Causes and Treatment of Hospital Gangrene as It Prevailed in the Confederate Armies, 1861-1865. In: Hamilton, F.H., Ed., Surgical Memoirs. War of the Rebellion, Collected and Published by the United States Sanitary Commission; Hurd and Houghton, Riverside Press, Cambridge.

[13] Riefler, J., Kosov, M. and Belotserkovskiy, M. (2015) The Treatment of a Gangrenous Leg. Clinical Infectious Diseases, 61, 1032-1033. https://doi.org/10.1093/cid/civ494

[14] Helling, T.S. and Daon, E. (1998) In Flanders Fields: The Great War, Antoine Depage. And the Resurgence of Debridement. Annals of Surgery, 228,173-181.

https://doi.org/10.1097/00000658-199808000-00005

[15] Murray C.K., Wilkins, K., Molter, N.C., Yun, H.C., Dubick, M.A., Spott, M.A., Jenkins, D., Eastridge, B., Holcomb, J.B., Blackbourne, L.H. and Hospenthal, D.R. (2009) Infections in Combat Casualties During Operations Iraqi and Enduring Freedom. Journal of Trauma, 66, S138-S144. https://doi.org/10.1097/TA.0b013e31819d894c

[16] Mandring, M.M., Hawk, A., Calhoun, J.H. and Andersen, R.C. (2009) Treatment of War Wounds: A Historical Review. Clinical Orthopedic Related Research, 467, 2168-2191. https://doi.org/10.1007/s11999-009-0738-5

[17] Meleny, F.L. (1924) Hemolytic Streptococcus Gangrene. JAMA Surgery, 9, 317-364. https://doi.org/10.1001/archsurg.1924.01120080083007

[18] Wilson, B. (1952) Necrotizing Fasciitis. American Surgeon, 18, 416-431.

[19] Shah, J., Sharma, J.M., O’Donoghue, B., Mearns, A.J. and Thomas, V. (2001) Necrotising Fasciitis of the Breast. British Journal Plastic Surgery, 54, 67-68. https://doi.org/10.1054/bjps.2000.3461

[20] Probstein, J. (1924) Gangrene of the Breast Complicating Diabetes. Annals of Surgery, 79, 79-81.

[21] Cai, Y., Cai, Y., Shi, W., Feng, Q. and Zhu, L. (2020) Necrotizing Fasciitis of the Breast: A Review of the Literature. Surgical Infections, 21, 1-11. https://doi.org/10.1089/sur.2020.071

[22] Konik, R.D. and Huang, G.S. (2020) Management of Primary Necrotizing Fasciitis 
of the Breast: A Systematic Review. Plastic Surgery (Oakv), 28, 215-221. https://doi.org/10.1177/2292550320928557

[23] Ravina, M.M. and Jamain (1949) Les Gangrenes du Sein Pendant la Lactation. Gynécologie et Obstétrique, 48, 49-55.

[24] Marcus, R. (1950) Haemolytic Streptococcal Gangrene of the Breast Successfully Treated with Streptomycin. British Medical Journal, 2, 394-395. https://doi.org/10.1136/bmj.2.4675.394

[25] Switzer, P.K. (1950) Gangrene of the Breast Associated with Diabetes Mellitus. The Journal of the South Carolina Medical Association, 46, 42-44.

[26] Boersma, D. and Engler, H. (1963) Gangrenous Breast from Venous Thrombosis. Surgery, 54, 876-879.

[27] Calandra, D.E., Cerdeiro, R., Pizzurno, H.E.N. and Guzman, N. (1969) Mammary Necrosis. Prensa médica Argentina, 56, 694-695.

[28] Archer, C.R. (1972) Case Study: Gangrene of the Breast. Nursing Mirror Midwives Journal, 134, 32-35.

[29] Kosloske, A.M., Cushing, A.H., Borden, T.A., Woodside, J.R., Klein, M.D., Kulasinghe, H.P. and Bailey, W.C. (1981) Cellulitis and Necrotizing Fasciitis of the Abdominal Wall in Pediatric Patients. Journal of Pediatric Surgery, 16, 246-251. https://doi.org/10.1016/S0022-3468(81)80673-2

[30] Goldberg, G.N., Hansen, R.C. and Lynch, P.J. (1982) Necrotizing Fasciitis in Infancy: Report of Three Cases and Review of the Literature. Pediatric Dermatology, 2, 55-63. https://doi.org/10.1111/j.1525-1470.1984.tb00444.x

[31] Archer, C.B., Rosenberg, W.M.C., Scott, G.W. and MacDonald, D.M. (1984) Progressive Bacterial Synergistic Gangrene in Patient with Diabetes Mellitus. Journal of the Royal Society of Medicine Supplement, 77, 1-3

[32] Eugster, T., Aeberhard, P., Reist, K. and Sakmann, K. (1997) Nekrotisierende Fasziitis durch B-hämolysierende Streptokoken mit letalem Ausgang-EinFallbericht. Swiss Surgery, 3, 117-120

[33] McAdoo, G.L. and Monif, G.R. (1997) Expanding Disease Spectrum Associated with Puerperal Mastitis. Infectious Diseases in Obstetrics and Gynecology, 5, 376-379. https://doi.org/10.1155/S1064744997000689

[34] Bodemer, C., Panhans, A., Chretien-Marquet, B., Cloup, M., Pellerin, D. and de Prost, Y. (1997) Staphyloccocal Necrotizing Fasciitis in the Mammary Region in Childhood: A Report of Five Cases. Journal of Pediatrics, 131, 466-469. https://doi.org/10.1016/S0022-3476(97)80080-7

[35] Banwell, P.E., Pereira, J. and Powell, B.W.E.M. (1998) Symmetrical Necrotising Chest Wall Infection following Paronychia. Case Reports, Journal of Accident and Emergency Medicine, 15, 58-59. https://doi.org/10.1136/emj.15.1.58

[36] Silva, M.A. da Costa, Fiho, J.B.S., Júnior, R.de F., Peleja, E.B., Catão, R.de A. and Ribeiro, L.F.J. (1998) Necrotizing Fasciitis of the Breast: Case Report. Revista Brasileira de Ginecologia e Obstetrícia, 20, 221-224. https://doi.org/10.1590/S0100-72031998000400008

[37] Sahoo, S.P., Khatri, A. and Khanna, A. (1998) Idiopathic Partial Gangrene of the Breast. Tropical Doctor, 28, 178-179. https://doi.org/10.1177/004947559802800320

[38] Sewell, G.S., Hsu, V.P. and Jones, S.R. (2000) Zoster Gangrenosum: Necrotizing Fasciitis as a Complication of Herpes Zoster. The American Journal of Medicine, 108, 520-521. https://doi.org/10.1016/S0002-9343(99)00395-2

[39] Frota Filho, J.D., Drews, C., Leães, P., Blacher, C., Tostes, F., Delatorre, N., Vieira, 
M., Lúcio, E., Pereire, W., Sales, M., Lobo, R., Stuermer, R., Tanaka, N., Portugal, L. and Luchese, F. (2001) Postoperative Necrotizing Fasciitis of the Thorax in Cardiac Surgery. Arquivos Brasileiros de Cardiologia, 76, 250-254. https://doi.org/10.1590/S0066-782X2001000300008

[40] Rangaswamy, M. (2001) Necrotizing Fasciitis: A 10-Year Retrospective Study of Cases in a Single University Hospital in Oman. Acta Tropica, 80, 169-175.

https://doi.org/10.1016/S0001-706X(01)00173-5

[41] Cunningham, J.D., Silver, L. and Rudikoff, D. (2001) Necrotizing Fasciitis: A Plea for Early Diagnosis and Treatment. The Mount Sinai Journal of Medicine, 68, 253-261

[42] Rege, S.A., Nunes, Q., Rajput, A. and Dalvi, A.N. (2002) Breast Gangrene as a Complication of Puerperal Sepsis. Archives of Surgery, 137, 1441-1442.

https://doi.org/10.1001/archsurg.137.12.1441

[43] Losanoff, J.E., Metzler, M.H., Richman, B.W., Cotton, B.A. and Jones, J.W. (2002) Necrotizing Chest Wall Infection after Blunt Trauma: Case Report and Review of the Literature. The Journal of Trauma, Injury, Infection, and Critical Care, 53, 787-789. https://doi.org/10.1097/00005373-200210000-00030

[44] Salhab, M., Al sarakbi, W. and Mokbel, K. (2005) Skin and Fat Necrosis od the Breast Following Methylene Blue Dye Injection for Sentinel Nose Biopsy in a patient with Breast Cancer. International Seminars in Surgical Oncology, 2, 26. https://doi.org/10.1186/1477-7800-2-26

[45] Rajakannu, M., Kate, V. and Ananthakrishnan, N. (2006) Necrotizing Infection of the Breast Mimicking Cancer. The Breast Journal, 12, 266-267.

https://doi.org/10.1111/j.1075-122X.2006.00253.x

[46] Nizami, S., Mohiuddin, K., Mohsin-e-Azam, Zafar, H. and Memon, M.A. (2006) Necrotizing Fasciitis of the Breast. The Breast Journal, 12, 168-169. https://doi.org/10.1111/j.1075-122X.2006.00227.x

[47] Tillet, R., Saxby, P.J., Stone, C.A. and Morgan, M.S. (2006) Group A Streptococcal Necrotizing Fasciitis Masquerading as Mastitis. The Lancet, 368, 174.

https://doi.org/10.1016/S0140-6736(06)69007-7

[48] Velchuru, V.R., Van Der Walt, M. and Sturzaker, H.G. (2006) Necrotizing Fasciitis in a Postmastectomy Wound. The Breast Journal, 12, 72-74. https://doi.org/10.1111/j.1075-122X.2006.00186.x

[49] Hanif, M.A. and Bradley M.J. (2008) Sonographic Findings of Necrotizing Fasciitis in the Breast. Journal of Clinical Ultrasound, 36, 517-519. https://doi.org/10.1002/jcu.20492

[50] Gehlen, J.M.L.G., Luyer, M.D.P., Keymeulenm, K. and Greve, J.W.M. (2008) Necrotizing Fasciitis Following Modified Radical Mastectomy. The Breast Journal, 14, 198-205. https://doi.org/10.1111/j.1524-4741.2007.00556.x

[51] Wong, C.-H. (2008) Necrotizing Fasciitis of the Breast. Plastic and Reconstructive Surgery, 122, 151e-152e. https://doi.org/10.1097/PRS.0b013e318186cd92

[52] Venkatramani, V., Pillai, S., Marathe, S., Rege, S.A. and Hardikar, J.V. (2009) Breast Gangrene in an HIV-Positive Patient. The Royal College of Surgeons of England, London, 91. https://doi.org/10.1308/147870809X401056

[53] Flandrin, A., Rouleau, C., Azar, C., Dubon, O. and Giacalone, P. L. (2009) First Report of a Necrotizing Fasciitis of the Breast following a Core Needle Biopsy. The Breast Journal, 15, 199-201. https://doi.org/10.1111/j.1524-4741.2009.00697.x

[54] Keune, J.D., Melby, S., Kirby, J.P. and Aft, R.L. (2009) Shared Management of a 
Rare Necrotizing Soft Tissue Infection of the Breast. The Breast Journal, 15, 321-323. https://doi.org/10.1111/j.1524-4741.2009.00731.x

[55] Dustagheer, S., Tohill, M.B. and Khan, K. (2009) Vacuum-Assisted Closure Dressing as an Aid to Salvage Brast following Severe Postoperative Infection. The Breast Journal, 15, 214-215. https://doi.org/10.1111/j.1524-4741.2009.00705.x

[56] Delotte, J., Karimdjee, B.S., Cua, E., Pop, D., Bernard, J-L., Bongain, A. and Benchimol, D. (2009) Gas Gangrene of the Breast: Management of a Potential Life-Threatening Infection. Archives of Gynecology and Obstetrics, 279, 70-81. https://doi.org/10.1007/s00404-008-0642-3

[57] Subramanian, A., Thomas, G., Lawn, A., Jackson, P. and Layer, G.T. (2010) Necrotising Soft Tissue Infection following Mastectomy. Journal of Surgical Case Reports, 1, 4. https://doi.org/10.1093/jscr/2010.1.4

[58] Vishwanath, G., Basarkod, S.I., Katageri, G.M. Mirji, P. and Mallapur, A.S. (2011) Necrotizing Fasciitis of the Breast with Shock and Postpartum Psychosis. Journal of Clinical and Diagnostic Research, 5, 1117-1119

[59] Luedders, D.W., Bohlmann, M.K., Hornemann, A., Dittmer, C., Diedrich, K. and Thill, M. (2011) Successful Application of Vacuum-Assisted Closure Therapy for Treatment of Mastitis-Associated Chronic Breast Wounds. Archives of Gynecology and Obstetrics, 283, 1357-1362. https://doi.org/10.1007/s00404-010-1594-y

[60] Wani, I., Bakshi, I., Parray, F.Q., Malik, A.A., Wani, R.A., Shah, M., Husasin, I., Malik, A., Wani, S. and Syed, W. (2011) Breast Gangrene. World Journal of Emergency Surgery, 6, 29. https://doi.org/10.1186/1749-7922-6-29

[61] Soliman, M.O., Ayyash, E.H., Aldahham, A. and Asfar, S. (2011) Necrotizing Fasciitis of the Breast: A Case Managed without Mastectomy. Medical Principles and Practice, 20, 567-569. https://doi.org/10.1159/000330026

[62] Lee, K.S., Seo, S.J., Park, M.C., Park, D.H., Kim, C.S., Yoo, Y.M. and Lee, I.J. (2011) Sepsis with Multiple Abscesses after Massive Autologous Fat grafting for Augmentation Mammoplasty: A Case Report. Aesthetic Plastic Surgery, 35, 641-645. https://doi.org/10.1007/s00266-010-9605-8

[63] Parker, J. and Sabanathan, S. (2001) Synergistic Gangrene of the Breast in a Patient with Type 2 Diabetes. Journal of the Royal Society of Medical Short Reports, 2, 74. https://doi.org/10.1258/shorts.2011.011099

[64] Adachi, K., Tsutsumi, R., Yoshida, Y., Watanabe, T., Nakayama, B. and Yamamoto, O. (2012) Necrotizing Fasciitis of the Breast and Axillary Regions. EJD, European Journal of Dermatology, 22, 817-818. https://doi.org/10.1684/ejd.2012.1838

[65] Rashid, O., Nagahashi, M. and Takabe, K. (2012) Management of Massive Soft Tissue Defects: the use of INTEGRA ${ }^{\oplus}$ Artificial Skin after Necrotizing Soft Tissue Infection of the Chest. Journal of Thoracic Diseases, 4, 331-335

[66] Reyman, T., Moore, T.A. and Seone, L. (2012). Serratia marcescens Necrotizing Fasciitis Presenting as Bilateral Breast Necrosis. Journal of Clinical Microbiology, 50, 3406-3408. https://doi.org/10.1128/JCM.00843-12

[67] Ablett, D.J., Bakker-Dyos, J. and Rainey, J.B. (2012) Primary Necrotizing Fasciitis of the Breast: A Case Report and Review of the Literature. Scottish Medical Journal, 57, 1-3. https://doi.org/10.1258/smj.2011.011283

[68] da Costa Vieira, R.A., Mathes, A.G.Z., Michelli, R.A.D., Ribeiro, G.F.H.P., Haikel, R.L., Viana, C.R., Paulo de Tarso Oliveira Castro, P.T.O. and Uemura, G. (2012) Necrotizing Soft Tissue Infection of the Breast: Case Report and Literature Review. Surgical Infections, 13, 270-275. https://doi.org/10.1089/sur.2011.029 
[69] Kaczynski, J., Dillon, M. and Hilton, J. (2012) Breast Necrotising Fasciitis Managed by Partial Mastectomy. British Medical Journal (BM) Case Reports, 1-3. https://doi.org/10.1136/bcr.02.2012.5816

[70] Salati, S.A. and Rather, A.A. (2012) Necrotizing Fasciitis of Breast. East and Central African Journal of Surgery, 17, 92-94.

[71] Singh, G. and Bharpoda, P. (2013) Necrotizing Fasciitis of Breast. Internet Journal of Medical Update, 8, 79-80.

[72] Miguélez, J.L.L., Wierhan, C.F., Perales, A.C., Martinez, T.D. and Valverde, M.L. (2013) Gangrena Gaseosa de la Mama. Revista Cubana de Cirugia, 52, 218-222.

[73] Pote, M.P., Kelkar, V.P., Bhople, L. and Patil, A. (2013) Necrotizing Fasciitis of the Breast: A Rare Presentation in Postpartum Mother. IOSR Journal of Dental and Medical Sciences, 11, 16-18. https://doi.org/10.9790/0853-1151618

[74] Meshoulam-Avital, D., Mizrahi, H., Zilberman, M. and Geron, N. (2014) Necrosis of the Breast: A Case Report and Review of the Literature. Research, 1, 924. https://doi.org/10.13070/rs.en.1.924

[75] Angarita, F.A., Acuna, S.A., Torregrosa, L., Tawil, M., Sánchez, E.F., Heilbron, O. and Domínguez, L.C. (2014) Bilateral Necrotizing Fasciitis of the Breast Following Quadrantectomy. Breast Cancer, 21, 108-114. https://doi.org/10.1007/s12282-010-0219-4

[76] Agrawal, S., Jayant, K. and Agarwal, R. (2014) Breast Gangrene: A Rare Source of Severe Sepsis. British Medical Journal (BM) Case Reports. https://doi.org/10.1136/bcr-2013-203467

[77] Yusuf, E., Steinrücken, J., Nordback, S. and Trampuz, A. (2014) Necrotizing Fasciitis After Breast Augmentation. Rapid Microbiologic Detection by Using Sonication of Removed Implants and Microcalorimetry. American Journal of Clinical Pathology, 142, 269-272. https://doi.org/10.1309/AJCPNA1ZKVK7PHUD

[78] Awe, O.O., Kesieme, E.B., Kayode-Adedeji, B. and Aigbonoga, Q.O. (2014) Necrotizing Fasciitis of the Chest in a Neonate in Southern Nigeria. Case Reports in Pediatrics, 2014, Article ID: 818059. https://doi.org/10.1155/2014/818059

[79] Mufty, H., Smeets, A. and Christiaens, M.-R. (2014) An Atypical Case of Necrotizing Fasciitis of the Breast. Acta Chirurgica Belgica, 114, 215-218. https://doi.org/10.1080/00015458.2014.11681013

[80] Kumar, M., Meeks, A. and Kearl, L. (2015) Necrotizing Fasciitis of the Chest Wall. Pediatric Emergency Care, 31, 656-660. https://doi.org/10.1097/PEC.0000000000000316

[81] Lee, J., Lee, K.J. and Sun, W.Y. (2015) Necrotizing Fasciitis of the Breast in a Pregnant Woman Successfully Treated Using Negative-Pressure Wound Therapy. Annals of Surgical Treatment and Research, 89, 102-106. https://doi.org/10.4174/astr.2015.89.2.102

[82] Yang, B., Connolly, S. and Ball, W. (2015) Necrotising Fasciitis of the Breast: A Rare Primary Case with Conservation of the Nipple and Literature Review. JPRAS Open Access, 6, 15-19. https://doi.org/10.1016/j.jpra.2015.05.002

[83] Kohayagawa Y., Ishitobi, N., Yamamori, Y., Wakuri, M., Sano, C., Tominaga, K. and Ikebe, T. (2015) Streptococcal Toxic Shock Syndrome from Soft-Tissue Infection of the Breast Caused by a Mucoid Type Strain. Journal of Infection and Chemotherapy, 21, 144-147. https://doi.org/10.1016/j.jiac.2014.08.031

[84] Pek, C.H., Lim, J., Ng, W., Lee, H.J., Ong, W.C., Foo, A.T.L., Lim, C.M., Thong, M., Sebastin S.J. and Lim, T.C. (2015) Extensive Necrotizing Fasciitis after Fat Grafting 
for Bilateral Breast Augmentation: Recommended Approach and Management. Archives of Plastic Surgery, 42, 365-367. https://doi.org/10.5999/aps.2015.42.3.365

[85] Lee, J.H., Lim, Y.S., Kim, N.G., Lee, K.S. and Kim, J.S. (2016) Primary Necrotizing Fasciitis of the Breast in an Untreated Patient with Diabetes. Archives of Plastic Surgery, 43, 613-614. https://doi.org/10.5999/aps.2016.43.6.613

[86] Tanwar, P., Gupta, S., Kumar, H., Meena, V.K., Goyal, A., Kalra, D., Khan, S.A. and Kumar, N.K. (2016) Bilateral Necrotizing Fasciitis of the Breast: A Case Report and Review of the Literature. IOSR Journal of Dental and Medical Sciences, 15, 80-82

[87] Mahran, K. and El-Heeny, A. (2016) A Case of Bilateral Breast Gangrene in Lactating Non Diabetic Young Lady. Indian Journal of Case Reports, 2, 90-92. https://doi.org/10.32677/IJCR.2016.v02.i04.002

[88] Besher, S.B. (2016) Necrotizing Fasciitis of the Breast. Hadhramut Journal of Medical Sciences, 5, 402-405.

[89] Brandt, W., Maxfield, M.W., Kim, A.W. and Davis, K.A. (2016) Necrotizing Soft Tissue of the Chest Wall. Trauma Surgery Acute Care Open, 1, 1-2. https://doi.org/10.1136/tsaco-2016-000005

[90] Rodríguez, J.Y., Rodríguez, G.J., Morales-López, S.E., Cantillo, C.E., Le Pape, P. and Álvarez-Moreno, C.A. (2016) Saksenaea Erythrospora Infection after Medical Tourism for Esthetic Breast Augmentation Surgery. International Journal of Infectious Diseases, 49, 107-110. https://doi.org/10.1016/j.ijid.2016.05.032

[91] Marongiu, F., Buggi, F., Mingozzi, M, Curcio, A. and Folli, S. (2017) A Rare Case of Primary Necrotising Fasciitis of the Breast: Combined Use of Hyperbaric Oxygen and Negative pressure Wound Therapy to Conserve the Breast: Review of the Literature. International Wound Journal, 14, 349-354. https://doi.org/10.1111/iwj.12607

[92] Bishi, P.R., Nayak, M.K. and Sahu, P. (2017) Breast Gangrene: A Rare Entity in Clinical Practice. Asian Journal of Pharmaceutical and Health Sciences, 7, 1698-1700.

[93] Ward, N.D., Harris, J.W. and Sloan, D.A. (2017) Necrotizing Fasciitis of the Breast Requiring Emergent Radical Mastectomy. The Breast Journal, 23, 95-99.

https://doi.org/10.1111/tbj.12686

[94] Fayman, K., Wang, K. and Curran, R. (2017) A Case Report of Primary Necrotising Fasciitis of the Breast: A Rare but Deadly Entity Requiring Rapid Surgical Management. International Journal of Surgery Case Reports, 31, 221-224. https://doi.org/10.1016/j.ijscr.2017.01.049

[95] Konik, R.D., Cash, A.D. and Huang, G.S. (2017) Necrotizing Fasciitis of the Breast Managed by Partial Mastectomy and Local Tissue Rearrangement. Case Reports in Plastic Surgery and Hand Surgery, 4, 77-80. https://doi.org/10.1080/23320885.2017.1364970

[96] Jha, P. and Jha, B.K. (2018) Case of Necrotizing Fasciitis of Breast in a Young Lactating Mother. Journal of the Institute of Medicine, 40, 134-136

[97] ALShareef, B. and ALSaleh, N. (2018) Necrotizing Fasciitis of the Breast: Case Report with Literature Review. Case Reports in Surgery, 20, Article ID: 1370680. https://doi.org/10.1155/2018/1370680

[98] Maldonado, G.C., Barbalho, D.M., Salum, F.C.A., Vita, M.I.C., Belem, R.F. and Vogt, M.F.B. (2018) Necrotizing Fasciitis of the Breast in Postpartum Period: Case Report. Mastology, 28, 110-113. https://doi.org/10.29289/2594539420180000348

[99] Cocco, D., Davis, J., Kowal-Vern, A., Wilson, W., Komenaka, I., Matthews, M.R. and Foster, K.N. (2019) Necrotizing Fasciitis of the Male and Female Breast: A Case Series. The Internet Journal of Plastic Surgery, 14, 1-7. 
[100] Won, Y-J., Hwang, J-Y., Moon, J.H., Ahn, S.K., Yang, I. and Woo, J.Y. (2019) Idiopathic Primary Necrotizing Fasciitis of the Breast: A Case Report. Journal of the Korean Society of Radiology, 80, 1265-1270. https://doi.org/10.3348/jksr.2019.80.6.1265

[101] Khatri, D., Shashikala, V., Mallikarjun, M. and Manoranjan U.D. (2019) Necrotizing Fasciitis of the Breast: A Case Report and Review of the Literature. Asian Journal of Case Reports in Surgery, 2, 1-5.

[102] Gupta, A., Gupta, A., Ravi, B., Mundra, M., Sandhu, H., Agrawal, S. and Anjun, R. (2019) Post-traumatic Necrotising fasciitis of the Breast: A Case Study with Literature Review. Journal of Wound Care, 28, 775-778. https://doi.org/10.12968/jowc.2019.28.11.775

[103] Tena, D. and Saa, L. (2019) Skin and Soft Tissue Infection Caused by Cutibacterium (formerly Propionibacterium) avidum: Report of Eleven Cases. Anaerobe, 56, 91-94. https://doi.org/10.1016/j.anaerobe.2019.02.013

[104] Fadaee, N., Ong, M. and Al-Askari, M. (2019) Necrotizing Fasciitis of the Breast: A Case Report and Literature Review. Journal of Medical Cases, 10, 288-292. https://doi.org/10.14740/jmc3361

[105] Stoeckl, E., Dedhia, P.H., Wilke, L.G. and Long, K.L. (2019) Necrotizing Soft Tissue Infection of the Breast: Bilateral Presentation in a Male Patient. Annals of Breast Surgery, 3, 19. https://doi.org/10.21037/abs.2019.08.04

[106] Ahmad, R. and Ahmad, M.E. (2019) Necrotizing Fasciitis of the Breast in a Non-Diabetic Postmenopausal Woman: A Case Report with a Review of the Literature. Journal of Medical Science and Clinical Research, 7, 600-601. https://doi.org/10.18535/jmscr/v7i3.109

[107] Marks, B., Fasih, T., Amonkar, S. and Pervaz, M. (2019) Necrotising Fasciitis of the Breast: A Rare but Deadly Disease. International Journal of Surgical Case Reports, 65, 10-14. https://doi.org/10.1016/j.ijscr.2019.10.020

[108] Maduba, C.C. and Nnadozie, U.U. (2020) Breast Necrotizing Fasciitis Following Stillbirth Managed with Nipple Areola Conservation in a Resource-Poor Setting: A Case Report. Journal of Surgical Case Reports, 2, 1-3. https://doi.org/10.1093/jscr/riz397

[109] Dodaro, C.A., Zaffiro, A., Iannicelli, A.M., Giordano, L., Sorbino, L., Mangiapia, F., Lanzano, M. and Schonauer, F. (2020) Combined Time Surgery and Conservative Management of Primary Necrotizing Fasciitis of the Breast: A Case Report. American Journal of Case Reports, 21, Article ID: e922688. https://doi.org/10.12659/AJCR.922688

[110] Chen, R.J., Gillespie, C., Jassal, K., Lee, J.C. and Read, M. (2020) Delayed Presentation of Breast Necrotising Fasciitis due to COVID-19 Anxiety. ANZ Journal of Surgery, 90, 1485-1487. https://doi.org/10.1111/ans.16102

[111] Kamagate, N. and De Vito, R. (2020) Necrotizing Soft Tissue Infection of the Breast During COVID-19 Pandemic. Case Reports in Surgery, 2020, 4 pp. https://doi.org/10.1155/2020/8876475

[112] Gillen, J., Verrico, E.V., McIntosh, V., Sussman, B., Abramson, D. and Tzeng, J. (2020) Case of Necrotizing Infection of the Breast and Brief Review of Literature. Breast Journal, 26, 1019-1021. https://doi.org/10.1111/tbj.13799

[113] Bhatt, A.A. and Khandelwal, A. (2021) Necrotizing Fasciitis: A True Emergency. Journal of Breast Imaging, 2021, 1-2.

[114] Yousfi, J., Oumlil, S, Benjilali, L. and Essaadouni, L. (2021)Necrotizing Fasciitis of 
the Breast Underlying an Autoimmune Disease. European Journal Case Reports in Internal Medicine, 8, 3 pp.

[115] Shivalingappa, S., Manjunath, K.N., Waiker, V., Kumaraswamy, M. and Odeyar, U. (2021) Necrotising Fasciitis: Appearance Can be Deceptive. World Journal of Plastic Surgery, 10, 43-52. https://doi.org/10.29252/wjps.10.1.43

[116] Rahim, G.R., Gupta, N., Maheshwari, P. and Singh, M.P. (2019) Monomicrobial Klebsiella Pneumoniae Necrotizing Fasciitis: An Emerging Life-Threatening Entity. Clinical Microbiology and Infection, 25, 316-323. https://doi.org/10.1016/j.cmi.2018.05.008

[117] Ng, D. and Frazee, B. ((2014) Necrotizing Fasciitis Caused by Hypermucoviscous Klebsiella Pneumoniae in a Filipino Female in North America. Western Journal of Emergency Medicine, 16, 165-168. https://doi.org/10.5811/westjem.2014.11.23599

[118] Flood, E.P., Redish, M.H., Bociek, S.J. and Shapiro, S. (1943) Thrombophlebitis Migrans Disseminata: Report of a Case in Which Gangrene of a Breast Occurred. Observations on the Theraupeutic Use of Dicumarol (3,3'methylenebis(4-hydroxycoumarin). New York State Journal of Medicine, 43, 1121-1124.

[119] Ejzenberg, D., Neusquen, L.P., Rolnik, D.L., Lozinsky, A.Z. and Piato, R.J. (2015) Breast Necrosis Induced by the Use of Coumadin: Case Report and Review of the Literature. Einstein (Sao Paulo), 13, 417-419. https://doi.org/10.1590/S1679-45082015RC2829

[120] Berry, M.M., Tavakkolizadeh, A. and Sommerlad, B.C. (2003) Necrotizing Ulceration after Breast Reduction. Journal of the Royal Society of Medicine, 96, 186-187. https://doi.org/10.1177/014107680309600408

[121] Tolkachjov, S.N., Fahy, A.S., Cerci, F.B., Wetter, D.A., Cha, S.S. and Camilleri, M.J. (2016) Postoperative Pyoderma Gangrenosum: A Clinical Review of Published Cases. Mayo Clinic Proceedings, 9, 1267-1279. https://doi.org/10.1016/j.mayocp.2016.05.001

[122] Mella, J.R. (2019) A Deceptive Diagnosis: Pyoderma Gangrenosum after Breast Surgery: A Case Series and Literature Review. Annals of Plastic Surgery, 83, S21-S30. https://doi.org/10.1097/SAP.0000000000002101

[123] Gesakis, K., Tanos, G., Onyekwelu, O., Gaitis, A. and Gudur, L. (2014) Primary Spindle Cell Sarcoma of the Breast Masquerading as Necrotizing Fasciitis. Journal of Surgical Case Reports, 2014, 1-3. https://doi.org/10.1093/jscr/rjt096

[124] Young, J.S. and Heffernan, D.S. (2021) Manifesting as a Case of Necrotizing Soft Fasciitis. Surgical Infection Society,

[125] Otero, T.M.N., Barber, S.R., Yeh, D.D. and Quraishi, S.A. (2017) Necrotizing Soft Tissue Infection or Sweet's Syndrome: Surgery vs No Surgery? A \& A Case Report, 8, 182-185. https://doi.org/10.1213/XAA.0000000000000459

[126] Kroshinsky, D., Alloo, A., Rothschid, B., Cummins, J., Tan, J., Montecino, R., Hoang, M.P., Duncan, L., Mihm, M. and Sepehr, A. (2012) Necrotizing Sweet's Syndrome: A New Variant of Neutrophilic Dermatosis Mimicking Necrotizing Fasciitis. Journal of the American Academy of Dermatology, 67, 945-954. https://doi.org/10.1016/j.jaad.2012.02.024

[127] Kostaras, E.K., Tanasarli, G.S. and Falagas, M.E. (2014) Use of Negative-Pressure Wound Therapy in Breast Tissues: Evaluation of the Literature. Surgical Infections, 15, 679-686. https://doi.org/10.1089/sur.2013.165

[128] Umbert, I.J., Winkelman, R.K., Oliver, G.F. and Peters, M.S. (1989) Necrotizing Fasciitis: A Clinical, Microbiological, and Histopathological Study of 14 Patients. Journal of the American Academy of Dermatology, 20, 774-781. 
https://doi.org/10.1016/S0190-9622(89)70089-X

[129] Abur, P.P., Yusufu, L.M. and Odigie, V.I. (2019) Necrotizing Fasciitis of the Breast in Ahmadu Bello University Teachjing Hospital, Zaria, Northwestern Nigeria. Archives of Medicine and Surgery, 4, 7-9. https://doi.org/10.4103/archms.archms 419

[130] Marchesi, A., Marcelli, S., Parodi, P.C., Perrotta, R.E., Riccio, M. and Vaienti, L. (2017) Necrotizing Fasciitis in Aesthetic Surgery: A Review of the Literature. Aesthetic Plastic Surgery, 41, 352-358. https://doi.org/10.1007/s00266-016-0754-2

[131] Sharma, D., Dalencourt, G., Bitterly, T. and Benotti, P.N. (2006) Small Intestinal Perforation and Necrotizing Fasciitis after Abdominal Liposuction. Aesthetics and Plastic Surgery, 30, 712-716. https://doi.org/10.1007/s00266-006-0078-8

[132] Zhang, M., Chen, L., Chi, K., Xu, L. and Li, Y. (2020) Necrotizing Fasciitis Complicated with Multiple Organ Dysfunction Syndrome After Breast Augmentation with Fat from Waist and Lower extremities: A Case Report. Journal of International Medical Research, 48, 1-5. https://doi.org/10.1177/0300060520937623

[133] Wong, C-H., Chang, H-C., Pasupathy, S., Khin, L-W., Tan, J-L. and Low, C. (2003). Necrotizing Fasciitis: Clinical Presentation, Microbiology, and Determinants of Mortality. Journal of Bone and Joint Surgery, 85-A, 1454-1460. https://doi.org/10.2106/00004623-200308000-00005

[134] Neeki M.M., Dong, F., Au, C., Toy, J., Khoshab, N., Lee, C., Kwong, E, Yuen, H.W., Lee, J., Ayvasian, A., Lux, P. and Borger, R. (2017) Evaluating the Laboratory Risk Indicator to Differentiate Cellulitis from Necrotizing Fasciitis in the Emergency Department. Western Journal of Emergency Medicine, 18, 684-689. https://doi.org/10.5811/westjem.2017.3.33607

[135] El-Men-Yar, A., Asim, M., Mudali, I.N., Mekkodathil, M., Latifi, R. and Al-Thani, H. (2017) The Laboratory Risk Indicator for Necrotizing Fasciitis (LRINEC) scoring: the Diagnostic and Potential Prognostic Role. Scandinavian Journal of Trauma, Resuscitation and Emergency Medicine, 25, 28. https://doi.org/10.1186/s13049-017-0359-z

[136] Fernando, S.M., Tran, A., Cheng, W., Rochwerg, B., Kyeremanteng, K. Seely, A.J. E., Inaba, K. and Perry, J.J. ( 2019) Necrotizing Soft Tissue Infection: Diagnostic Accuracy of Physical Examination, Imaging, and LRINEC Score: A Systematic Review and Meta-Analysis. Annals of Surgery, 269, 58-65.

https://doi.org/10.1097/SLA.0000000000002774

[137] Abdullah, M., McWilliams, B. and Khan, S.U. (2019) Reliability of the Laboratory Risk Indicator in Necrotising Fasciitis (LRINEC) Score. The Surgeon, 17, 309-318. https://doi.org/10.1016/j.surge.2018.08.001

[138] Nawijn, F., Smeeing, D.P.J., Houwert, R.M., Leenen, L.P.H. and Hietbrink, F. (2020) Time Is of the Essence When Treating Necrotizing Soft Tissue Infections: A Systemic Review and Meta-analysis. World Journal of Emergency Surgery, 15, 4. https://doi.org/10.1186/s13017-019-0286-6

[139] Gelbard, R.B., Ferrada, P., Yeh, D., Williams, B.H., Loor, M., Yon, J., Mentzer, C., Khwaja, K., Khan, M.A., Kohli, A., Bulger, E.M. and Robinson, B.R.H. (2018) Optimal Time of the Initial Debridement for Necrotizing Soft Tissue Infection: A Practical Management Guideline from the Eastern Association for the Surgery of Trauma. Journal of Trauma and Acute Care Surgery, 85, 208-214. https://doi.org/10.1097/TA.0000000000001857 